University of Nebraska - Lincoln

DigitalCommons@University of Nebraska - Lincoln

USDA Wildlife Services - Staff Publications

U.S. Department of Agriculture: Animal and Plant Health Inspection Service

2010

\title{
Contraceptive Efficacy of a Novel Intrauterine Device (IUD) in White-Tailed Deer
}

\author{
Karl D. Malcolm \\ University of Wisconsin, Madison, Department of Forest and Wildlife Ecology \\ Timothy R. Van Deelen \\ University of Wisconsin, Madison, Department of Forest and Wildlife Ecology \\ David Drake \\ University of Wisconsin, Madison, Department of Forest and Wildlife Ecology \\ Darrel J. Kesler \\ University of Illinois, Urbana, Department of Animal Sciences \\ Kurt C. VerCauteren \\ USDA-APHIS-Wildlife Services, kurt.c.vercauteren@usda.gov
}

Follow this and additional works at: https://digitalcommons.unl.edu/icwdm_usdanwrc

Part of the Environmental Sciences Commons

Malcolm, Karl D.; Van Deelen, Timothy R.; Drake, David; Kesler, Darrel J.; and VerCauteren, Kurt C., "Contraceptive Efficacy of a Novel Intrauterine Device (IUD) in White-Tailed Deer" (2010). USDA Wildlife Services - Staff Publications. 937.

https://digitalcommons.unl.edu/icwdm_usdanwrc/937

This Article is brought to you for free and open access by the U.S. Department of Agriculture: Animal and Plant Health Inspection Service at DigitalCommons@University of Nebraska - Lincoln. It has been accepted for inclusion in USDA Wildlife Services - Staff Publications by an authorized administrator of DigitalCommons@University of Nebraska - Lincoln. 


\title{
Contraceptive efficacy of a novel intrauterine device (IUD) in white-tailed deer
}

\author{
Karl D. Malcolm ${ }^{\mathrm{a}, *}$, Timothy R. Van Deelen ${ }^{\mathrm{a}}$, David Drake ${ }^{\mathrm{a}}$, \\ Darrel J. Kesler ${ }^{\mathrm{b}}$, Kurt C. VerCauteren ${ }^{\mathrm{c}}$ \\ a Department of Forest and Wildlife Ecology, University of Wisconsin, 1630 Linden Drive, Madison, WI 53706-1598, USA \\ b Department of Animal Sciences, University of Illinois, 106 Animal Sciences Laboratory, Urbana, IL 61801, USA \\ c USDA/APHIS/WS National Wildlife Research Center, 4101 LaPorte Avenue, Fort Collins, CO 80521-2154, USA
}

\section{A R T I C L E I N F O}

\section{Article history:}

Received 27 December 2008

Received in revised form 22 April 2009

Accepted 4 May 2009

Available online 9 May 2009

\section{Keywords:}

Contraception

Fertility control

Intrauterine device

White-tailed deer

\begin{abstract}
A B S T R A C T
Overabundant white-tailed deer (Odocoileus virginianus) pose risks to property, health, and safety of human beings. Public concerns about lethal management can impair efforts to address these issues, particularly in urban settings. Several techniques developed for reducing reproductive output of deer have limited utility because they require repeated dosing to achieve permanent effect and face uncertain regulatory approval for use beyond experimentation. From 10 August 2006 through 30 December 2007, we evaluated the contraceptive efficacy of copper-containing intrauterine devices (IUDs) implanted trans-cervically in white-tailed deer at the E.S. George Reserve in Pinckney, Michigan. Intrauterine devices were implanted before $(n=9)$ and shortly after $(n=10)$ the breeding season. Post-breeding season IUD treatment was in conjunction with a $5 \mathrm{~cm}^{3}$ dose of $5 \mathrm{mg} / \mathrm{ml}$ prostaglandin $\mathrm{F}_{2 \alpha}\left(\mathrm{PGF}_{2 \alpha}\right)$, delivered subcutaneously. Intrauterine devices reduced pregnancy rates when administered prior to breeding $(P<0.001)$ and prevented pregnancy for up to 2 years (the duration of the study). Two of 8 does that received IUDs prior to the breeding season and survived to the end of the study became pregnant (due to loss of the implant) during the second year while all $(n=16)$ does without implants conceived. Cervical changes associated with early pregnancy made trans-cervical implantation after the breeding season challenging, and resulted in improperly placed IUDs in 2 treated does. The apparent expulsion of IUDs by pregnant does that received the combined treatment after breeding suggests IUD treatment should be limited to the pre-breeding season. Intrauterine devices show potential as a tool for small-scale deer population management via non-steroidal reproductive inhibition.
\end{abstract}

(c) 2009 Elsevier B.V. All rights reserved.

\section{Introduction}

Efforts to reduce white-tailed deer (Odocoileus virginianus) densities in urban areas are often met with diverse challenges that can make management intractable. Though regulated hunting is the preferred tool for managing deer

\footnotetext{
* Corresponding author at: Department of Forest and Wildlife Ecology, University of Wisconsin, A224 Russell Labs, 1630 Linden Drive, Madison, WI 53706-1598, USA. Tel.: +1 608265 7595; fax: +1 6082629922.

E-mail address: malcolm@wisc.edu (K.D. Malcolm).
}

populations in the United States, it can be difficult to employ due to safety concerns and public opposition to lethal removal (DeNicola et al., 2000; Messmer et al., 1997). Increasing deer range and densities in exurban refugia, combined with decreasing hunter numbers, threaten the future efficiency of sport hunting as a deer management tool that is universally applicable (Brown et al., 2000).

Public pressure to adopt non-traditional (i.e., nonlethal) management approaches for deer has catalyzed research on fertility control (Kirkpatrick and Rutberg, 2001). Use of chemicals for reproductive control of freeranging deer, a potential human food, requires navigating a 
complicated regulatory approval process (Kirkpatrick and Jöchle, 2005). The risk of non-target exposure precludes effective steroids from consideration for fertility control in free-ranging wildlife (DeNicola et al., 1997).

Work focused on extending the efficacy of non-lethal contraceptive and contra-gestation treatments has resulted in improved formulations (Locke et al., 2007). Still, aside from surgical sterilization, proven non-lethal contraceptive and contra-gestation approaches used in white-tailed deer generally require repeated treatment for lifelong reproductive suppression, particularly in areas without hunting, where the lifespan of deer is considerably longer (Miller et al., 2004; Waddell et al., 2001). Repeatedly treating individual free-ranging deer increases the difficulty of each subsequent treatment attempt, as deer become more wary. Therefore, long-lasting treatment effect is a key characteristic to consider when evaluating contraceptives for application to overabundant deer. We tested the contraceptive efficacy of flexible, copper-containing, C-shaped intrauterine devices (IUDs) designed specifically for nonsurgical use in deer over multiple breeding seasons. We hypothesized that this novel design would be easily delivered under field conditions, would result in reliable implant retention in the uterine body, and would be capable of preventing pregnancies in white-tailed deer for at least two breeding seasons without surgery or the use of steroids.

\section{Materials and methods}

\subsection{Study site}

We conducted IUD trials on the University of Michigan's Edwin S. George Reserve (ESGR), located in southeastern Michigan. The ESGR was enclosed with a 3.0-4.3 m high deer-proof fence that contained approximately 525 ha of predominately grassy old fields and oak-hickory (Quercus, Carya) woodlands (University of Michigan, 2008). We marked does with ear tags and radio collars at the time of capture and allowed them to range freely within the study site thereafter.

\subsection{IUD design}

Flexible, C-shaped IUDs (Fig. 1) were manufactured for trans-cervical delivery using a standard artificial insemination gun designed for use in goats (Capra aegagnus, Hoegger Goat Supply, Fayetteville, GA). Previous studies have shown that IUD implantation into 1 uterine horn (of a bicornuate uterus) does not necessarily prevent pregnancy in the contralateral horn (Sanyal et al., 2007). For this reason, and due to the difficulty of non-surgically implanting uterine horns individually under field conditions, we designed IUDs to be implanted in the uterine body. The strong antifertility effects associated with copper (Roblero et al., 1996) prompted the inclusion of a $0.95 \mathrm{~cm}$ long coil of fine copper wire between 2 medical implant-grade elastomer (Dow Corning, Midland, MI) end sections. When flexed straight, implants were cylindrical, $4.50 \mathrm{~cm}$ in length, and $0.24 \mathrm{~cm}$ wide, while in a relaxed C-shape were $2.80 \mathrm{~cm}$ long and $1.60 \mathrm{~cm}$ wide. One end of each IUD was equipped with a $0.37 \mathrm{~cm}$ diameter spherical bulb that extended beyond the

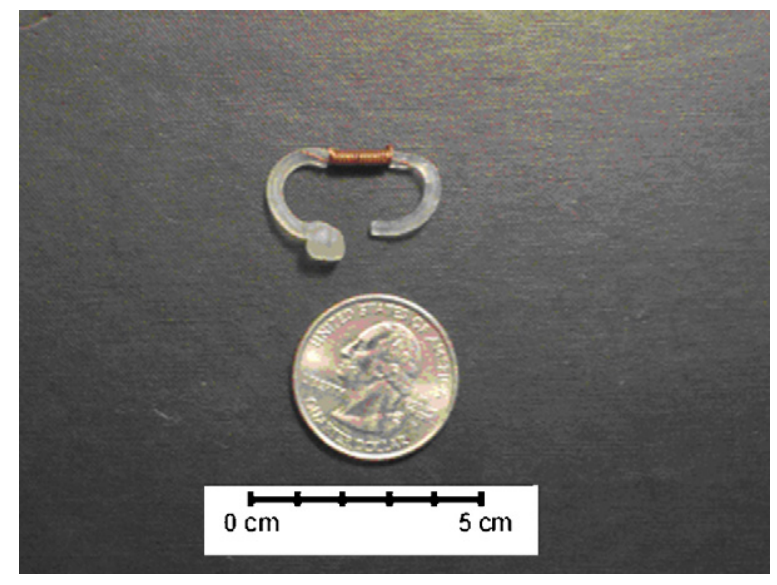

Fig. 1. Intrauterine device (IUD) designed for trans-cervical delivery in female white-tailed deer. IUDs consisted of medical implant-grade elastomer and a copper wire coil.

tip of the loaded delivery tube. The smooth surface of the implant bulb aided passage of the lubricated tube through the cervix during delivery.

\subsection{IUD treatment}

From 10 August 2006 to 29 September 2007, 24 adult $(\geq 1$ year) does were captured using drop nets, rocket nets, netted-cage traps, and darting. Does were immobilized with $3.0-5.0 \mathrm{mg} / \mathrm{kg}$ xylazine hydrochloride and $2.5-5.5 \mathrm{mg} / \mathrm{kg}$ Telozol delivered intramuscularly (Amass and Drew, 2005). Prior to release, $3 \mathrm{mg} / \mathrm{kg}$ Tolazoline hydrochloride was administered intravenously. Does were assigned to one of three treatment groups: pre-breeding season IUD treatment, sham IUD treatment (delivery procedure with no IUD implanted), and early post-breeding season IUD plus $\mathrm{PGF}_{2 \alpha}\left(5 \mathrm{~cm}^{3}\right.$ of $5 \mathrm{mg} / \mathrm{ml}$, subcutaneous) combined treatment. Pregnancy statuses of 12 adult does culled on the ESGR from 21 December 2006 through 20 January 2007 were recorded to determine the pregnancy rate among those that received no treatment.

With sedated does placed in sternal recumbency, a sterilely lubricated speculum and artificial insemination light were used to locate the cervical opening transvaginally. The artificial insemination tube, containing the implant, was also lubricated then passed through the external cervical os cervical rings leading to the uterine body. Once the tip of the delivery tube reached the cervico-uterine junction, the plunger was used to expel the implant into the uterus.

Nine does were implanted with IUDs prior to the breeding seasons of 2006 ( 10 August-6 October, $n=5$ ) and 2007 (15-22 August, $n=4)$. Dates of conception on the ESGR have not been recorded earlier than 19 October (McCullough, 1979). We assigned 5 does to the sham IUD treatment group during 2006 ( $n=2$, captured 18 August and 17 September) and 2007 ( $n=3$, captured 17 August-29 September) to determine if delivery techniques caused reproductive tract damage that could compromise the ability of does to conceive independent of IUD implantation. Aside from no implant being delivered during the procedure, sham treat- 
Table 1

Pregnant relative to total number of female white-tailed deer given various contraceptive IUD treatments compared to untreated controls (culled 21 December 2006-20 January 2007) at the University of Michigan Edwin S. George Reserve, Pinckney, Michigan, 2006-07. Ratios (2007) include surviving does captured during 2006 and those added during the 2007 field season.

\begin{tabular}{|c|c|c|c|c|}
\hline \multirow[t]{2}{*}{ Treatment } & \multicolumn{2}{|l|}{2006} & \multicolumn{2}{|l|}{2007} \\
\hline & Pregnant & Total number & Pregnant & Total number \\
\hline Pre-breeding IUD & 0 & 4 & $2^{\mathrm{a}}$ & $8^{a}$ \\
\hline Post-breeding IUD and $\mathrm{PGF}_{2 \alpha}$ & 5 & 9 & $8^{b}$ & $9^{b}$ \\
\hline Sham IUD procedure & 2 & 2 & $4^{\mathrm{ab}}$ & $4^{\mathrm{ab}}$ \\
\hline Control & & & $12^{\mathrm{b}}$ & $12^{\mathrm{b}}$ \\
\hline
\end{tabular}

a,b Values in the same column with different superscript letters differ $(P<0.01$; Fisher's exact test).

ment was identical to that of does treated with IUDs before the breeding season.

We implanted 10 does with IUDs after the breeding season, from 21 December 2006 through 14 January 2007 (approximately 35 and 59 days into gestation, McCullough, 1979), using the same delivery protocol. In addition to receiving an IUD, each doe treated after the breeding season was administered a $5 \mathrm{~cm}^{3}$ injection of $5 \mathrm{mg} / \mathrm{ml}$ Lutalyse ${ }^{\circledR}$ subcutaneously (Pharmacia and Upjohn, Peapack, NJ). Blood $\left(5 \mathrm{~cm}^{3}\right)$ was collected by jugular venipuncture prior to release to determine pregnancy status (BioTracking LLC, Moscow, ID).

Efficacy of IUD treatment was assessed during both years of the study. In summer 2007 (June-August), radiomarked does were located and visually observed at least once per month. Reproductive success of treated does was determined by recording the presence or absence of fawns with them during field observations. Effectiveness of IUD treatment during the second breeding season of the study (2007) was assessed from 20 to 30 December 2007, when does from all treatment groups were relocated, euthanized via sharpshooting, and necropsied. Reproductive tracts were examined for implant retention and evidence of pregnancy. Because recognizable embryos are not visible until about 30 days gestation (McCullough, 1979), ovaries of does without visible fetuses were evaluated for corpora lutea of pregnancy (Mansell, 1971). Pregnancy rates of each IUD treatment group were compared to untreated controls using Fisher's exact test (Maindonald and Braun, 2007). The University of Wisconsin-Madison Research Animals Research Center approved this study as described in research protocol A1267.

\section{Results}

Does treated with IUDs before the breeding season had lower pregnancy rates than those without IUDs. None of the 4 does treated prior to breeding in 2006 were observed with fawns the following summer (Table 1). Examination of reproductive tracts from treated does after two breeding seasons indicated that contraceptive effect of pre-breeding IUDs was maintained over both breeding seasons in 3 of the 4 that survived to that point. In contrast, all 12 untreated, culled does were pregnant at necropsy $(P<0.01)$. Three of 4 does that were treated for a single season were also prevented from conceiving for an overall IUD efficacy rate of 6 of $8(P<0.001$, Table 1$)$. The 2 does treated prior to breeding that became pregnant expelled the IUD $(n=1)$ or experienced drift of the implant from the uterine body to the uterine horn $(n=1)$. In the latter case the doe carried a fetus with advanced maceration in the horn opposite the IUD. One doe treated prior to breeding died during the winter following treatment and was scavenged before cause of death could be determined.

Analysis of blood samples collected from does treated with IUD plus $5 \mathrm{~cm}^{3}$ of $5 \mathrm{mg} / \mathrm{ml} \mathrm{PGF}_{2 \alpha}$ after the breeding season indicated that 9 of 10 were pregnant at capture. One pregnant doe died approximately 3 months following capture and was scavenged before cause of death could be determined. Based on field observations during summer 2007, at least 5 of the surviving 8 pregnant does delivered fawns despite treatment with $\mathrm{PGF}_{2 \alpha}$ during early gestation. Fawns were first observed with 3 of 5 does from the post-breeding season treatment in late July and early August (possibly indicating late births) while both 2006 sham-treated does were observed with fawns in June. Necropsy results indicated that none of the 8 pregnant does treated post-breeding with the IUD plus PGF $_{2 \alpha}$ combination retained implants within the uterus and all conceived the year after treatment. Improper implant delivery resulting from cervical constriction was evident (IUDs were recovered outside reproductive tract) in 2 does treated after the breeding season. The single post-breeding treated doe that was not pregnant at treatment retained the IUD and failed to conceive the following year. Pregnancy rates among does that received the post-breeding season IUD treatment did not differ from controls $(P=0.36$, Table 1).

The IUD delivery procedure we implemented did not compromise fertility. All does that received the sham IUD treatment and survived until the end of the study period $(n=4)$ and all other treated does that expelled $(n=7$, one pre-breeding season treatment, six post-breeding season treatment) or had improperly placed implants $(n=2$ post-breeding season treatment) were pregnant upon examination of reproductive tracts.

\section{Discussion}

Prevention of pregnancy caused by IUD treatment prior to the breeding season in deer is consistent with trials in other ruminants (Chander and Gupta, 1977; Hawk et al., 1968, 1974). Though the mechanisms responsible for preventing pregnancy vary across species, IUDs generally block conception by altering the chemical and physical environ- 
ment of the uterus with effects lasting until removal of the implant (Ortiz et al., 1996). Results from the present study are consistent with observations of efficacy extending until removal or loss of the IUD. IUDs delivered to does prior to breeding prevented conception for up to two breeding seasons (the duration of the study) when they were retained in the uterine body. Furthermore, pregnancies only occurred following expulsion of the IUD or movement into a uterine horn. This point underscores the value of IUD designs that maximize retention rates and may warrant future comparative trials with multiple IUD designs. Effective IUD designs must account for the impressive motility of the uterus, which (in sheep) contracts from the uterine body anteriorly an average of 4-7 times per minute during early estrus, and may dislodge implants from the body of the uterus (Hawk, 1975).

Efforts to extend the effective treatment period into the early post-breeding season by combining IUD delivery with $\mathrm{PGF}_{2 \alpha}$ were unsuccessful in the present study. Three explanations exist for post-breeding season IUD treatment failure: (1) pregnancy-induced cervical blockage prevented proper implant placement, (2) IUDs were expelled with conceptuses following successful pregnancy termination, and (3) treatment failed to terminate pregnancies and IUDs were expelled at parturition. Evidence exists that each possibility may have played a role in the present study: (1) IUDs recovered outside the reproductive tracts of 2 postbreeding season treated does indicated cervical blockage and improper delivery, (2) observations of presumably lateborn fawns accompanying 3 properly implanted does that were treated after the breeding season likely indicate loss of first pregnancy, IUD expulsion, and rebreeding, and (3) 1 properly implanted post-breeding season doe observed with a single fawn in mid-June of 2007 may have carried the initial pregnancy to term and expelled the implant at birth. Previous attempts to abort pregnancies using $\mathrm{PGF}_{2 \alpha}$ in white-tailed deer have experienced mixed results with stage of gestation, stress, and method of delivery all potentially impacting rates of induced luteolysis (Becker and Katz, 1994; DeNicola et al., 1997; Plotka et al., 1983; Waddell et al., 2001).

The IUD tested in these trials has important advantages to other methods of non-lethal reproductive control for deer. Unlike surgical sterilization, the delivery protocol can be accomplished by individuals with a minimal amount of training and equipment, and therefore at a lower cost. Compared to surgical sterilization, the trans-cervical delivery of this IUD is less invasive, which results in less risk of post-treatment infection. Because treated free-ranging deer can enter the human food chain, implanting them with small, inert IUDs is an excellent way to avoid unintended effects on people. In contrast, the use of some systemic chemical reproductive control agents could have unforeseen consequences for non-target animals (e.g., scavengers) and human beings. Furthermore, IUDs similar in composition to those we tested over two breeding seasons have been used for long-term contraception in women with pregnancy rates as small as one pregnancy per 100 treated individuals per year (Newton and Tacchi, 1990). Barring expulsion it is therefore plausible that a single IUD treatment could outlast the lifespan of implanted does.

\section{Conclusions}

IUDs are best suited to application in small, isolated herds because attempts to apply this tool to large populations of free-ranging deer would be met with the extreme costs and logistical challenges of handling many individual does. Non-steroidal IUDs do not prevent ovulation, and repeated estrous cycles in treated does could disrupt herd sociobiology (McShea et al., 1997). Although this poses a possible drawback to IUD treatment, the ability to prevent pregnancy without disrupting estrous cycles has potential applications in research.

\section{Acknowledgements}

We thank E. Berkley, W. Bolgos, P. Burke, N. Gillespie, G. Jacobs, M. Lavelle, M. Lechmaier, E. Love, S. Love, R. Malcolm, A. Shakoor, D. Storm, R. Walrath, M. Watt, and E. Wilson for assistance with fieldwork. We greatly appreciate the logistical support of the University of Michigan Edwin S. George Reserve Committee, particularly E. Werner and C. Davis. The USDA National Wildlife Research Center and the University of Michigan provided financial support.

\section{References}

Amass, K.D., Drew, M., 2005. Chemical immobilization of animals technical field notes: 2005. In: Safe-Capture International, Incorporated, Mount Horeb, Wisconsin, USA.

Becker, S.E., Katz, L.S., 1994. Effects of exogenous prostaglandin $F_{2 \alpha}\left(P_{G F}\right)$ on pregnancy status in white-tailed deer. Zoo Biol. 13, 315-323.

Brown, T.L., Decker, D.J., Riley, S.J., Enck, J.W., Lauber, T.B., Curtis, P.D., Mattfeld, G.F., 2000. The future of hunting as a mechanism to control white-tailed deer populations. Wildlife Soc. Bull. 28, 797-807.

Chander, S., Gupta, R.C., 1977. Effect of intrauterine device on ovarian function in goats. Theriogenology 8, 271-280.

DeNicola, A.J., Kesler, D.J., Swihart, R.K., 1997. Remotely delivered prostaglandin $F_{2 \alpha}$ implants terminate pregnancy in white-tailed deer. Wildlife Soc. Bull. 25, 527-531.

DeNicola, A.J., VerCauteren, K.C., Curtis, P.D., Hygnstrom, S.E., 2000. Managing White-tailed Deer in Suburban Environments: A Technical Guide. Cornell Cooperative Extension, Ithaca, NY, USA.

Hawk, H.W., 1975. Uterine contractions in the estrous ewe. Biol. Reprod. $12,423-430$

Hawk, H.W., Conley, H.H., Brinsfield, T.H., 1968. Studies on the antifertility effect of intrauterine devices in the cow. Fertil. Steril. 19, 411-418.

Hawk, H.W., Cooper, B.S., Conley, H.H., 1974. Effects of a copper intrauterine device on embryo survival, uteri spermicidal activity, and endometrial vascular porosity in the ewe. Am. J. Obstet. Gynecol. 118, 480-484.

Kirkpatrick, J.F., Rutberg, A.T., 2001. Fertility control in animals. In: Salem, D.J., Rowan, A.N.(Eds.), The State of the Animals: 2001. Humane Society Press, Gaithersburg, MD, USA, pp. 183-198.

Kirkpatrick, J.F., Jöchle, W., 2005. Regulatory Issues. In: Asa, C.S., Porton, I.J. (Eds.), Wildlife Contraception: Issues, Methods, and Applications. The Johns Hopkins University Press, Baltimore, MD, USA, pp. 17-25.

Locke, S.L., Cooke, M.W., Harveson, L.A., Davis, D.S., Lopez, R.R., Silvy, N.J., Fraker, M.A., 2007. Effectiveness of Spayvac ${ }^{\circledR}$ for reducing white-tailed deer fertility. J. Wildlife Dis. 43, 726-730.

Maindonald, J., Braun, J., 2007. Data Analysis and Graphics Using R: An Example-based Approach, Second ed. Cambridge University Press, New York, NY, USA.

Mansell, W.D., 1971. Accessory corpora lutea in ovaries of white-tailed deer. J. Wildlife Manage. 35, 369-374.

McCullough, D.R., 1979. The George Reserve Deer Herd: Population Ecology of a K-selected Species. University of Michigan Press, Ann Arbor, MI, USA.

McShea, W.J., Monfort, S.L., Hakim, S., Kirkpatrick, J., Liu, I., Turner Jr., J.W., Chassy, L., Munson, L., 1997. The effect of immunocontraception on the behavior and reproduction of white-tailed deer. J. Wildlife Manage. 61, 560-569. 
Messmer, T.A., George, S.M., Cornicelli, L., 1997. Legal considerations regarding lethal and nonlethal approaches to managing urban deer. Wildlife Soc. Bull. 25, 424-429.

Miller, L.A., Rhyan, J., Killian, G., 2004. GonaCon ${ }^{\mathrm{TM}}$, a versatile GnRH contraceptive for a large variety of pest animal problems. In: Proceedings of the 21st Vertebrate Pest Conference, Published at University of California, Davis, pp. 269-273.

Newton, J., Tacchi, D., 1990. Long-term use of copper intrauterine devices, a statement from the Medical Advisory Committee of the Family Planning Association and the National Association of Family Planning Doctors. Lancet 335, 1322-1323.

Ortiz, M.E., Croxatto, H.B., Bardin, C.W., 1996. Mechanisms of action of intrauterine devices. Obstet. Gynecol. Surv. 51, 42S51S.
Plotka, E.D., Seal, U.S., Verme, L.J., Ozoga, J.J., 1983. The adrenal gland in white-tailed deer: a significant source of progesterone. J. Wildlife Manage. 47, 38-44.

Roblero, L., Guadarrama, A., Lopez, T., Zegers-Hochschild, F., 1996. Effect of copper ion on the motility, viability, acrosome reaction and fertilizing capacity of human spermatozoa in vitro. Reprod. Fertil. Dev. 8, 871-874.

Sanyal, R., Banerjee, S., Taori, K., 2007. Pregnancy and IUD in different horns of the uterus. J. Clin. Ultrasound 35, 40-41.

University of Michigan, 2008. Edwin S. George Reserve home page. http://sitemaker.umich.edu/esgr/home. (Accessed 28.01.2008).

Waddell, R.B., Osborn, D.A., Warren, R.J., Griffin, J.C., Kesler, D.J., 2001. Prostaglandin $\mathrm{F}_{2 \alpha}$-mediated fertility control in captive white-tailed deer. Wildlife Soc. Bull. 29, 1067-1074. 